\title{
RIPENESS AND READINESS THEORIES IN INTERNATIONAL CONFLICT RESOLUTION
}

\section{Aytekin Cantekin}

\begin{abstract}
This paper offers a theoretical perspective on the relationship between ripeness theory and readiness theory within the structuralism paradigm of international mediation as a part of international conflict resolution. In order to do so, it explains the foundations of international mediation and these theories in question, discusses their primary notions and further argues and offers some practical generalizations for conflict analysis. It suggests that, first using readiness theory to understand each party separately, then using ripeness theory to map the bilateral coordination may be a better way to grasp basic foundations and change dynamics of the conflict to catch the 'ripe' moment.
\end{abstract}

\section{Keywords}

Theories in international conflict resolution, conflict, mediation, leadership

\section{Introduction}

The UN General Assembly unanimously accepted a resolution about 'strengthening the role of mediation in the peaceful settlement of disputes, conflict prevention and resolution' on 28 July 2011 . This resolution recognized the increased use of mediation, reflected on current challenges facing the international community in such mediation efforts, and called on key actors to develop their mediation capabilities (The United Nations, 2012, 2). Indeed, mediation, besides direct negotiations between the parties, is one of the most effective methods to avoid, manage and resolve international disputes and conflicts.

International conflicts can show up as economic, environmental as well as political or securityrelated. But international political and security issues have somewhat different features from economic or environmental ones in which the parties' orientation will not be as strongly competitive. The political and security issues take place within a context of power politics, and the power-centred struggles and relationships have a major effect on international mediation. This premise is the conceptual basis of the analysis of the motives of mediation parties, the conditions that affect the performance and roles of mediators and the cues to their effectiveness (Touval and Zartman, 1989, 116). 


\section{Mediation in International Conflict Resolution}

In general, mediation is a process in which a third party guides disputants through a nonadversarial discussion process that has as its goal the settling of disputes. The third party is expected to be genuinely impartial. It is generally accepted that the third party has no direct stake in the outcome and has no power to impose a decision (Isenhart and Spangle, 2000, 72). Mainstream mediation describes impartiality as an important feature of the activity. But some suggest that impartiality is not a condition in international mediation as there are biased mediators' examples.

International mediation generally refers to mediation activities conducted by various international actors with the aim of managing international conflicts on interstate and intrastate levels. Third parties who might have an interest in mediating these conflicts can be representatives of states (neighbouring countries, global powers, etc.), representatives of global or regional organizations (The UN, EU, etc.), global NGOs (such as international aid or religious organizations) and even individuals (such as Carter, Tutu, Ahtisaari) with or without a formal mandate (Vukovic, 2014, 63).

It would be rare for governments and international organizations to engage in mediation for only humanitarian reasons. In reality, mediation necessitates more than willingness. An important investment of political, moral, and material resources on the part of the mediator or country should be addressed by the mediation process, and the fact that mediators may be no less motivated by self- interest than by humanitarian desires. To some extent, mediators are players in the plot connections surrounding a dispute or conflict, and have some interest in the outcome. They may want to promote their own interests or extend and increase influence. Otherwise, they may not be prepared to mediate. This statement is also true for contending parties. They start the mediation process because they expect the mediator's intervention to work in their favour (Touvaland Zartman, 2015, 117-118). Every party should accept the mediator before the mediation starts and this decision also belongs to the parties in discussion in international relations.

Some conditions are necessary for beginning a mediation process whatever the skills of the mediator are. These conditions constitute a set of starting postures that bring the contenders to mediation and continue to influence the course of events and outcome during the mediation process. A broad list of these factors that must be present for mediation from the parties to have a high potential for success (Isenhart and Spangle, 2000, 75-76) is below:

- A stalemate or crisis situation in which the parties are willing to allow a third party to help them resolve the dispute,

- Willingness to engage in collaborative discussion on theissues,

- The interests or goals are interdependent,

- Voluntary participation and capability to create a mutually agreeable settlement,

- Willingness to suspend hostilities, threats, and intimidation during the process,

- Contribution of all parties who effect the dynamics of the conflict,

- Acceptance of the mediator to all parties. 
Some scholars suggest a more limited framework on when does the mediation work. Beer and Stief portray five conditions $(2007,7)$ :

- A resolution, or at least a desire for change,

- All the important stakeholders come to the table,

- The contenders are (eventually) able to express the reasons for their discomfort and distress,

- The mediator is capable to control and sustain the process,

- Capability of the parties for living up to their promises.

The UN describes three issues (The UN, 2012, 5):

- The main conflict parties must be open to trying to negotiate a settlement,

- A mediator must be accepted, credible and well supported,

- There must be a general consensus at the regional and international levels to support the process.

Timing is an important part of mediation and mediating activity. Especially in international conflicts, all intermediaries or mediating bodies face a critical problem of timing. When are third party involvements likely to be welcomed by parties involved in an intense, long-lasting conflict? When is an intermediary likely to be relevant or irrelevant? These questions are also connected with the ending phase of a conflict or leaders inclining towards terminating a conflict. Chris Mitchell describes some crucial factors relevant to leaders considering terminating a conflict bilaterally $(2015,77-78)$ :

- The perceived distance from attaining the goals in conflict,

- The perceived probability of eventually attaining these desired goals,

- The availability of further resources to continue to conflict behaviour in pursuit of the desired goal,

- The relative value of the goal in conflict compared with otherobjectives,

- The resources already used in pursuit of these goals, which will add to the desirability of the original goals, and the extent of the existing sacrifices made during the conflictinter-action.

There has been a growing interest in international mediation since early 1960s and the number of studies on different dimensions of international mediation has increased steadily. This issue was reflected by several seminal literature reviews on the topic (Wall, 1981; Wall and Lynn, 1993; Wall et al., 2001; Duursma, 2014). For example, wall et al. (2001) dealt with the international mediation in four different phases: The interactions of parties before mediation, mediation, mediator's approach and the outcomes. Duursma distinguished between three sections (2014): Antecedents of mediation, mediation approaches and the outcomes.

Analysing mediation raises some interests and questions about what the third party can do in a conflict, under what circumstances, and to what effect. Two major paradigms dominate the debate over these issues: The structuralist and the social- psychological paradigms of mediation. The structuralist paradigm is constructed on a basis that through the use of persuasion, incentives, and disincentives (such as costing process), rivals to a conflict can be led to and through a negotiated settlement. This paradigm 
accepts that the causes of conflicts are objective issues that can yield to negotiation. On the other hand, the social-psychological paradigm of mediation focuses on the processes of communication and exchange as a way to change perceptions and attitudes. According to this paradigm, conflicts reflect subjective, phenomenological, and social fractures and third parties can change the perceptions, attitudes, values and behaviours of the parties to a conflict (Crocker et al., 2003, 22-23).

After these short explanations on international mediation, this article will focus on foundations, similarities and differences between ripeness and readiness approaches which are mainly related to the first phase of international mediation or antecedents of international mediation.

It is very obvious that the relationship between the mediator and the conflict/conflict parties is quite complex in every type of mediation effort. But if the mediator bloc has also various multi-parties, the relationship's complexity becomes very complicated and this is the situation for most of international mediations. Thus, this complexity is one of the issues to be solved and arranged beforehand during the negotiation or mediation process.

International mediation was not a new discovery in the aftermath of the World War II. But the bipolarity and the mutual nuclear deterrence pushed the international community and great powers to try to solve many interstate and intrastate conflicts with international mediation efforts. Conflicts over political and security issues take place within a context of international power politics and this context has a major effect on international mediation which has some different features from other types of mediation.

Many of these interstate and intrastate conflicts are protracted, deep rooted and intractable. They are intense, inescapable strivings over issues such as critical resources, identity, meaning, justice, and power. They are complicated, traumatic, and often resist even the most serious negotiation or mediation initiatives towards resolution. The protracted, deep rooted and intractable conflicts contain some characteristics distinguishing them from more tractable, resolvable conflicts. They are extraordinary because of their high degree of intransigence, complexity, persistence, and malignancy. They are complex, nonlinear, self-sustaining systems of idiosyncratic nature (Coleman, 2003, 4). The five general characteristics of the protracted, deep rooted or intractable conflicts are remarkable (Coleman et al., 2008b, 44-45):

1. They have many different sources of conflict located at multiple levels such as individual, group, communal and their interaction with each other often feed or sustain hostilities.

2. They are often situated in places where other community problems (unemployment, housing, nutrition problems etc.) exist and cause 'conflict traps' by resulting in long-term patterns of misery and trauma.

3. The sources of hostilities in these settings (issues, leaders, policies etc.) often change constantly and at any given time might be more or less determining of the conflict.

4. Each case is different and has its own set of factors. Generalisations from one case to another are frequently problematic.

5. They tend to be resistant to traditional or familiar methods of peace-making and they often continue to 
exist.

Because of these features, the protracted, deep rooted and intractable conflicts differ from other types of conflict, and the resolution of them asks the negotiators and mediators to have more skills and to make more efforts than the others. Ripeness theory and readiness theory provide two important frameworks in order to deal with these types of international conflicts.

\section{Ripeness Theory}

Ripeness theory is one of the most influential theories of motivation and conflict resolution in the field today (Coleman et al., 2008a, 4). It is William Zartman's theoretical approach to the study of conflict resolution in studies starting from the 1980s. He published several studies on this theory (for example: 1986, 1989, 1995, 2000, 2001). In his opinion, two factors are centrally important for finding a solution by negotiation or mediation to an international conflict: the substance of proposals and timing of efforts. He focuses on the timing of efforts.

The ripe moment is described in the dictionary as the juncture in a dispute when the parties are most inclined (perhaps out of exhaustion) to make a settlement and when, therefore, it is best to start a negotiation or force the pace of an existing one (Berridge and James, 2003, 233). Zartman defends that substantive proposals are fruitless until the moment is ripe for parties. Ripeness is a necessary condition for the initiation of negotiations, bilateral or mediated. It must be seized by the parties or by the mediator. The mediator must specify the meaning and evidence of ripeness in order that the conflicting parties can fruitfully start mediation sessions. It is predictive in identifying some elements necessary for the productive initiation of the mediation (Zartman, 2000, 225-227). These are mutually hurting stalemate and perception of way out.

\section{Mutually Hurting Stalemate (MHS)}

The first necessary element is the parties' perception of a mutually hurting stalemate (MHS). When the parties find themselves locked in a situation from which they cannot escalate to victory and this deadlock is hurting both of them, they look for a relief. The hurt or pain is not necessarily in equal degrees or for the same reasons (Zartman, 2000, 228). A hurting stalemate is actually a painful deadlock, while an imminent catastrophe resembles a deadline, which the contenders would be afraid to miss as they fear that their situation might further deteriorate. MHS can be described in short as lengthy periods of violence, from which neither of the fighting parties are likely to get out of through a unilateral victory, a state of military stalemate (Schrodt et al., 2003, 2-3). Zartman describes a 'plateau' and 'deadlock' for one party when it is unable to achieve its aims. This is a situation of nowhere to go. Zartman looks also for the other party to arrive at a similar perception or in his words 'plateau' to catch the ripe moment. If the parties to a conflict cannot feel or understand this perception, the mediator should persuade them about the situation (Zartman, 1989, 268). Third party has an important role to play here. 


\section{Perception of Way Out}

The second necessary element for a ripe moment is the parties' perception of a way out. They want but cannot identify a specific solution. Both of them have a simultaneous sense that a negotiated solution is possible to reach. The conflict is ripe for the solution, if the parties perceive themselves to be in a hurting stalemate and perceive the probability of a way out (a negotiated or mediated solution). The MHS can have an objective basis. But the most important thing is that the parties must perceive this situation as a MHS. At this point this notion has a subjective character for the mediation, not an objective one. Of course, the greater the objective evidence, probably the greater the subjective perception of a stalemate will be. The mediators should see and seize the ripe moment and turn it into mediation and negotiations. If only objective elements of ripeness exist mediators can push the parties to feel and understand the MHS (Zartman, 2000, 228-232).

\section{Initial Ripeness}

Negotiation between the main adversaries is only one feature in conflict resolution. Some of the most important functions of pre-mediation or pre-negotiation, such as finding valid spokespersons and constructing support and coalitions for negotiations have intraparty characteristics. Initial ripeness or prenegotiation is a fluid concept and this phase could extend as far back as when the parties first considered negotiation or mediation as a way out of armed conflict, and extend forward into the formal bargaining phase. Pre-negotiation begins when one or more parties consider negotiation or mediation as an option and communicate this intention to other party or parties (Lilja, 2011, 313-314). Hence, this intention is not an intra- party secret anymore and should be signalled somehow.

Initial ripeness paves the way to the mediation and negotiations. If the conflict is not ripe for solution, efforts are generally fruitless. One of the main conditions relies on the ripeness idea that parties resolve their conflict when they are ready to do so.

\section{Emergence of Substantive Proposals}

The presence of willing, resourceful and acceptable mediators, who possibly bring to the table concrete plans for getting out of the status quo situation, fulfils the condition of 'a way out' for Zartman. This possible and alternative way out can also be created by internal actors within the parties (Schrodt et al., 2003, 3). The mediator should focus on the positions and generate possible substantive proposals to give a real way out to the parties. Ripeness propositions should account for the possibility that the parties will develop their interests. The mediator or the third party should explore and provide concrete alternatives to the parties at this stage. With these substantive proposals, the parties can understand that there are other ways to protect their interests while still controlling the outcome. 


\section{Leadership for the Way Out}

The leaders and/or the followers of the contending parties can perceive themselves in a hurting stalemate and start to look for a way out. Leaders, realising that the status quo cannot continue in this hurting stalemate, should lead this change. These leaders can be the current political leaders, or new leaderships can arise. This necessity draws further attention to the internal political issues of the parties. A sufficient compromise on both sides is a necessity to allow leaders to persuade their colleagues and citizens that the interests of the party is protected. They must be able to sell the agreement to their constituents (Lieberfeld, 1999, 76-77). A competition for intraparty leadership and the building of support for negotiations should take place. Without intraparty acceptances to negotiations, the prospects for success in talks or mediation will be small (Lilja, 2011: 314).

\section{The Pull Factor of a Mutually Enticing Opportunity}

In some instances, the opportunity for a solution grows more attractive as the issue of the conflict becomes older, no longer justifying hostile relations with the other party or the mediator that it imposed. Such initiatives might be termed mutually enticing opportunities. The mutually enticing opportunities are important in the broader negotiation process and have a place in extending ripeness theory. An MHS is the necessary and insufficient condition for negotiation or mediation to start. But the negotiators must provide the prospects for a more acceptable, attractive future in order to pull them out of their conflict. The push factor has to be replaced by a pull factor, in the form of a formula for agreement and prospects of reconciliation that the parties could design during the negotiation or mediation process. This is the function of mutually enticing opportunities that can provide new acceptable solutions for the change of mentalities to reconciliation (Zartman, 2000, 241-243). Mutually enticing opportunities might create key transformation possibilities for the parties in the negotiation or mediation process.

\section{Ripeness for a Solution}

Mediators should look and search for a ripe moment for the solution during their interactions with the parties even at the peak of hostilities. Zartman gives some examples to catch the ripe moment (2000, 232-235). After the breakup of Yugoslavia, Richard Holbrooke found this ripe moment in 1995 to have the Dayton Agreement between the three main parties. Chester Crocker felt the appropriate ripe environment in the Angolan war in 1988 was to get the Tripartite Accord between Angola, Cuba and South Africa. Alvaro de Soto endorsed the necessity of ripeness in his mission to mediate a peace in El Salvador.

The ripeness of the parties for a solution plays an important role and, in this phase, the third party or the mediators have several policy options to persuade the parties to reach an agreement. The 2008 Djibouti-Eritrea border dispute and the Qatari mediation might be an example. In June 2008, a strife erupted along the Eritrean- Djiboutian border. In June 2010, the Qatari mediation was able to bring 
the two parties to mediation. This provides an example of the importance of the mediator in bringing reluctant parties to an understanding that negotiation initiation may be in their interests. This case also provides an example of conflict management (Frank, 2015, 114, 131-133). Although a peace agreement of the mediation process has yet to be finalised, the mediation efforts created a peace period and stability. The mediator can make some concrete attempts to ensure ripeness to the parties for a solution.

\section{Critics}

Several additional studies on ripeness theory have been published from different points of view. For example, Hancock (2001) examined different conceptions of ripeness to evaluate their usefulness to war termination theory and practice. He concluded that ripeness theory needs to have a systemic combination of its objective and subjective elements and a collaboration between track I (official actors like governments) and track II (unofficial actors such as NGOs) interveners in order to create proper conditions in the conflict (2001, 203-204). Another researcher argues that claims of ripeness theory's prediction when conflicts are ripe for resolution are unsustainable (O’Kane, 2006, 280-283). Amer argues that Zartman's theoretical approach may have some explanatory value in the resolution of the conflict situation at the internal Cambodian level. But no explanatory value is identified at the regional and global levels (Amer, 2007, 739-740). There are also critics on the situations where MHS is perceived but the response is to increase resistance rather than consider alternatives (Frank, 2015, 116). Lederach provides a critique of the guiding 'ripeness' metaphor and proposes a reorientation of the practice of developing negotiated peace processes. He has three main points (2003, 31-34):

1. Ripeness is a rear-view mirror in reality. It proposes to provide a predictive capacity. However, peacebuilding generally, and negotiations in particular, have not entailed a ripeness process like the seasonal maturation of an apple moving from blossom to red, juicy and ready-to-eat fruit. In his opinion, ripeness may be most useful in retrospect, but is extremely weak in its predictive capacity from the standpoint of a practitioner.

2. Ripeness is more often than not a notion perceived by outsiders with the luxury of dispassionate facts and factors. In the course of week-to-week and month-to-month emergencies people rarely see their situations as 'ripe' for peace. Ripeness is in the eye of the beholder. The process is not linear but circular and linear. However, ripeness depends on a linear metaphor of time and change.

3. Ripeness theory sees mediator action as cherry picking. This is the result of two problematics commonly held understandings or beliefs. The first one is a belief that mediation lies in the person of the mediator-as-the-actor rather than mediation-as-process with multiple roles and functions accomplished by a wide array of actors. The second one is that the success of mediation is primarily judged by a production of an agreement rather than creation of constructive change. Ripeness suggests the cherry is the agreement and that picking the cherry is like a mediation harvest. 


\section{Readiness Theory}

Readiness theory, with the description of his author, is a revision and elaboration of Zartman's ripeness theory. Readiness theory differs from Ripeness in that it uses variables rather than necessary states and focuses on a single party rather than both parties to a conflict. The Readiness notion is a characteristic of one party reflecting the thinking of its leadership with regard to conflict with the other party and it might vary within a wide scale of conciliatory behaviour. Readiness advances conciliatory behaviour (Pruitt, 2007, 1524-1525). Pruitt argues that his point of view as an extension of ripeness is better able to fit historical cases as well as being more heuristic, with its ability to include more elements of conflict mediation outcomes (2005). For Pruitt, readiness has two components which combine in a multiplicative way: Motivation to end the conflict and optimism about the outcome of conciliation and negotiation or mediation.

\section{Motivation and Optimism}

From the perspective of one party, there is a sense that the conflict is unwinnable or contains unacceptable costs or risks and/or a pressure exists from powerful third parties such as allies for the motivation. The sense that one is losing creates greater motivation. The existence of both motivation and optimism are compulsory, even in some degree (Pruitt, 2015, 9-10; 2007, 1525).

The leaderships of the parties have four tactical course of action: continue current hostilities, escalate the conflict, seek allies and finally explore or enter negotiation or mediation. The first three tactics are unilateral, the fourth one is bilateral or multilateral. Generally, after trying all the unilateral tactics and concluding their un-workability, the party to the conflict can end up with negotiation or mediation (Pruitt, 200,1525-1526). This doesn't exclude the possibility of deciding on the fourth tactic anywhere in the conflict cycle. Motivation to end the conflict lies in the fourth course of action for leaders of the contending parties.

Optimism refers to the possibility of concluding negotiations with an agreement that is acceptable to the contending parties. Optimism about negotiation results from three states of mind: lowered aspirations, working trust and perceived light at the end of the tunnel. Lowered aspirations mean achievable goals. Working trust shows the belief the other party also wants to escape the conflict. The perception that an acceptable agreement is shaping up and this is a perceived light at the end of the tunnel for the party (Pruitt, 2007, 1529).

\section{Central Coalition Theory}

The generalization of readiness theory to the multiparty case is central coalition theory. It is assumed that the parties who enter and stay in a mediation all have (less or much) motivation to end the conflict and optimism about negotiation. Every member has a position in the political spectrum of the conflict and can be hawk, moderate or dove. The hawks of each party have more extreme goals and are less flexible about making concessions. By contrast, doves share some peace perspectives and try to 
understand the nature of the conflict by contacting the other party and looking for solutions. Readiness for negotiation/mediation is smallest for the hawks and greatest for the doves. There are also members between hawks and doves, namely moderates in each party. Negotiations or mediations generally involve doves and neutrals of each party to reach peace agreements, and often include both to be successful. So, the participants in such negotiations or mediations can be called a central coalition. Central coalitions vary in size from very broad including most hawks, to very narrow covering only doves of both parties (Pruitt, 2007, 1531-33).

\section{Critics}

There are limited case studies conducted to rate the explanatory power of the readiness theory. One of them is Schiff's study (2013) on the Aceh (Helsinki) peace process. The analysis of this process in the Aceh conflict demonstrates that readiness theory (motivation and optimism) enables the researchers to identify and map many more factors that influence conflict resolution processes than any other theory in the field. Despite this conclusion, some shortcomings are highlighted and they derive from its comprehensiveness and complexity (Schiff, 2013, 54). In the Djibouti-Eritrea dispute, motivation and optimism, key concepts of the readiness theory, are difficult to associate with Eritrea (Frank, 2015, 133). An explicit need for more case studies exists for measuring the explanatory power of the readiness theory.

\section{Discussion}

If parties are incapable of reaching an accommodation, they may try to enlist the services of a third party. There are several forms of third party involvement. Where the third party becomes actively engaged in the negotiations such as submitting some possible solutions to the parties, it is common to speak of mediation or mediating activities. Article 33 of UN Charter adds a list of possible ways to settle disputes peacefully, most of those being of a political nature (Klabbers, 2015, 141). This reflects generally the local, regional or global power relations of international politics and sometimes international organizations and institutions. In relation to these activities, both Zartman and Pruitt indicate and try to explain importance of timing and they share many common points.

A general approach necessitates scrutiny and an understanding of both the mutual interaction among the parties and every party's change of position in the course of events. Ripeness theory aims at and explains the mutual interaction. Mutual hurting stalemate, search for a way out with other party's approach are consequences of bilateral relationships and interactions. Ripeness theory looks for MHS and finding both of them in the middle of the 'plateau'.

Both approaches focus on timing of efforts for negotiation or mediation, and they accept that parties resolve their issue when they are ready to so. Zartman gives more importance to bilateralism. He underlines that the alternative to the solving the issue at the same time is that the means of achieving a satisfactory result are blocked and the parties find themselves in an uncomfortable and costly predicament. In his opinion, the metaphor of ripeness is easy to comprehend, yet its apparent simplicity 
has also led to some confusion and misunderstanding even among those who have written about it. He says ripeness is a necessary but not sufficient condition for the start of negotiation, bilateral or mediated (Zartman, 2000, 225-226). On the other hand, readiness theory gives the researchers the ability to understand each party individually. Readiness theory's interest mainly focuses on one party and it is useful to investigate and comprehend the parties to the conflict separately. It is a vehicle to understand each party's position usingvariables.

Zartman thinks that readiness theory is an extension the notion of ripeness into the negotiations. He indicates that Pruitt underlines that parties can come to the willingness/perception for different reasons, at different speeds, and even at different times, as well as the need for both parties to sense that there is a way out (and hence to sense that the other party so senses). Zartman insists that the need for mutual dependence as an element in ripeness could be tested. He writes that such discussions miss some of the original points and emphasize others in an effort to better grasp the essence of ripeness theory.

A step-by-step methodology could be more useful to study the international conflict from a third-party perspective. Motivation and optimism levels of the parties to the conflict indicated by readiness theory could be searched and scaled by a third-party in order to measure MHS of ripeness theory and then decide the right timing of a mediating activity.

The MHS is a bilateral situation. To see the right moment in the conflict between the parties, it is an absolute necessity to study the degree of motivation and optimism of every party. Therefore, theoretically, first using readiness theory to understand each party and its positions separately, then using ripeness theory to map the bilateral coordination can be a better way to grasp basic foundations and change dynamics of the conflict to catch the ripe moment.

This model can be very useful in tackling hard problem type conflict analysis. In this type of conflict, participants are adversaries and the goal of each of them is victory (Fisher and Ury, 2012, 11-12). These specifications are very common for interstate and intrastate armed struggles. It should be indicated that this analytical approach, first readiness theory for each party then ripeness theory for mutual understanding of the conflict, is only a theoretical proposal at the moment and necessitates case studies and more discussion.

Timing is an important part of the problem to the conflict, yet there are others. One of them is short term and long term consequences. Beardsley asserts that third-party involvement through mediation can construct the prospects for peaceful bargains for the better in the short term but for the worse in the long term. In the short term, mediation can provide incentives that enlarge the set of bilaterally acceptable alternatives, give post-conflict security guarantees, help the parties to recognize appropriate offers, and create political cover for concessions for leaders. But in the long term, the involvement of a third-party can structure artificial incentives for peace that don't persist, interfere with the capacity for the actors to fully understand the bargaining framework, and enable the parties to stall in hopes of obtaining an advantage during the peace process (Beardsley, 2015:234). This raises some new research questions. What type of relationship exists between the MHS or ripe moments and short term/long term outcomes of the conflict? This question also necessitates more research and discussion. 


\section{Conclusion}

International conflict is social conflict and could result in war. After experiencing its devastating effects in recent history, countries created international organizations and institutions to solve international conflicts in peaceful ways. Yet conflicts and wars continue to exist and international negotiation/mediation efforts from third parties have important roles to play even they are not for only humanitarian reasons.

Timing of these efforts is an important dimension of conflict intervention or resolution. Zartman and Pruitt have some similar explanations of this timing point. Zartman's ripeness theory defends that ripeness is a necessary condition for the initiation of negotiations, either bilateral or mediated and it must be seized by the parties or by the third-party/mediator. The two necessary elements of ripeness are perceptions of mutually hurting stalemate (MHS) and a way out. The MHS is when the parties find themselves locked in a situation from which they cannot escalate to victory and this deadlock is hurting both of them and they look for a relief.

Pruitt's readiness theory is a revision and elaboration of ripeness theory. Readiness theory differs from ripeness theory in that it uses variables rather than necessary states and focuses on a single party rather than both parties to a conflict. He argues that two components are important for readiness: motivation to end the conflict and optimism about the outcome of conciliation and negotiation or mediation.

Finally, a comprehensive approach including both readiness and ripeness theories may be more useful. This approach suggests that first using readiness theory to understand each party separately, then using ripeness theory to map the bilateral coordination can be a better way to grasp basic foundations and change dynamics of the conflict to catch the ripe moment. 


\section{REFERENCES}

Amer, Ramses (2007) 'The Resolution of the Cambodian Conflict: Assessing the Explanatory Value of Zartman's Ripeness Theory', Journal of Peace Research, 44: 6, 729-742.

Berridge, G.R. and Alan James (2003) A Dictionary of Diplomacy. Second Edition, Hampshire: Palgrave Macmillan.

Coleman, Peter T. (2003) 'Characteristics of Protracted, Intractable Conflict: Toward the Development of AMetaframework-I', Peace and Conflict: Journal of Peace Psychology, Vol.9, No.1, 1-37.

Coleman, Peter T. et al. (2008a) 'Reconstructing Ripeness I: A Study of Constructive Engagement in Protracted Social Conflicts', Conflict Resolution Quarterly, Vol.26, No.1, Fall Issue, 3-42.

Coleman, Peter T. et al. (2008b) 'Reconstructing Ripeness II: Models and Methods for Fostering Constructive Stakeholder Engagement Across Protracted Divides', Conflict Resolution Quarterly, Vol.26, No.1, Fall Issue, 43-69.

Crocker, Chester A. et al. (2003) 'Multiparty Mediation and the Conflict Cycle' in Crocker, Chester A., Fen Osler Hampson and Pamela Aall (Eds.), Herding Cats: Multiparty Mediation in a Complex World.Washinghton, DC: US Institute of Peace Press, 19-45.

Duursma, Allard (2014) 'A Current Literature Review of International Mediation', International Journal of Conflict Management, 25:1, 81-98.

Fisher Roger and William Ury, with Bruce Patton (Ed.) (2012) Getting to Yes: Negotiating Agreement Without Giving In. New York: Random House.

Frank, Kevin K. (2015) 'Ripeness and the 2008 Djibouti-Eritrea Border Dispute',

Northeast African Studies, Vol.15, No.1, 113-138.

Hancock, Landon E. (2001) 'To Act or Wait: A Two-Stage View of Ripeness', International Studies Perspectives, 2, 195-205.

Isenhart, Myra Warren and Michael Spangle (2000) Collaborative Approaches to Resolving Conflict. Thousand Oaks: Sage Publications.

Klabbers, Jan (2015) International Law. Cambridge: Cambridge University Press.

Lederach, John Paul (2003) 'Cultivating Peace: A Practitioner's View of Deadly Conflict and Negotiation', in John Darby, Roger MacGinty (Eds), ComtemporaryPeacemaking: Conflict, Violence and Peace Processes, New York: Palgrave Macmillan, 30-37.

Lieberfeld, Daniel (1999) 'Conflict "Ripeness" Revisited: The South African and Israeli/Palestinian Cases', Negotiation Journal, Vol.15, No.1, January, 63-82.

Lilja, Jannie (2011) 'Ripening Within? Strategies Used by Rebel Negotiators to End Ethnic War', Negotiation Journal, Vol.27, No.3, July, 311-342.

Mitchell, Chris R. (2015) 'The Structure of International Conflict', in Tom Woodhouse et al. (Eds.), The Contemporary Conflict Resolution Reader. Cambridge: Polity, 77-80.

O'Kane, Eamonn (2006) 'When Can Conflicts Be Resolved? A Critique of Ripeness', Civil Wars, Vol.:8, No.:3-4, 268-284. 
Pruitt, Dean G. (2005) Whither Ripeness Theory? Working Paper No.25, Institute for Conflict Analysis and Resolution, Virginia: George Mason University.

Pruitt, Dean G. (2007) 'Readiness Theory and the Northern Ireland Conflict', American Behavioral Scientist, 50:11, 1520-1541.

Pruitt, Dean G. (2015) 'The Evolution of Readiness Theory', in Mauro Galluccio (Ed.), Handbook of International Negotiation: Interpersonal, Intercultural, and Diplomatic Perspectives. Switzerland: Springer International Publishing, 123-138.

Schiff, Amira (2013) 'On Success in Peace Processes: Readiness Theory and the Aceh Peace Process', Peace and Conflict Studies, Vol.20, No.1,27-57.

Schrodt, Philip A., Ömür Yılmaz, and Deborah J.Gerner (2003) 'Evaluating "Ripeness" and "Hurting Stalemate" in Mediated International Conflicts: An Event Data Study of the Middle East, Balkans, and West Africa', Paper prepared for delivery at the Annual Meeting of the International Studies Association, Portland, Oregon, February.

Touval, Saadia and I.William Zartman (1989) 'Mediation in International Conflicts' in Kenneth Kressel et al., Mediation Research: The Process and Effectiveness of Third-Party Intervention.San Francisco: Jossey-Bass Publishers, 115-137.

United Nations (2012) The United Nations Guidance for Effective Mediation. New York: United Nations.

Vukovic, Sinisa (2014) 'International Mediation as a Distinct Form of Conflict Management', International Journal of Conflict Management, 25:1, 61-80.

Wall, J. (1981), 'Mediation: An Analysis, Review, and Proposed Research', Journal of Conflict Resolution, 25: 1,157-180.

Wall, James A., and Lynn, Ann (1993), 'Mediation: A Current Review', Journal of Conflict Resolution, 37: 1, 160-194.

Wall, James A., Stark John B., Standifer, Rhetta L. (2001), 'Mediation: A Current Review and Theory Development", Journal of Conflict Resolution, 45: 3, 370-391.

Zartman, I.William (1986) 'Ripening Conflict, Ripe Moment, Formula and Mediation' in Diane BenDahmane and John McDonald (Eds.), Perspectives on Negotiation.Washington, DC: Government Printing Office.

Zartman, William (1989) Ripe for Resolution: Conflict and Intervention in Africa. Updated Edition, A Council on Foreign Relations Book, New York: Oxford University Press (First Edition in 1985).

Zartman, William (1995) 'Dynamics and Constraints in Negotiations in Internal Conflicts', in William Zartman (Ed.), Elusive Peace: Negotiating an End to Civil Wars, Washington, DC: Brooking Institution, 3-29.

Zartman, William (2000) 'Ripeness: The Hurting Stalemate and Beyond', in Paul C.Stern et al., International Conflict Resolution After the Cold War, Washington, DC: National Academies Press, 225-250.

Zartman, William (2001) 'Preventive Diplomacy: Setting the Stage', in WilliamZartman (Ed.), Preventive Negotiation: Avoiding Conflict Escalation, Boulder, CO: Rowman \& Littlefield, 1-18. 
Aytekin Cantekin is a Jean Monnet visiting research scholar (Turkish Government EU Ministry, Ankara) in residence at Maynooth University, Edward M Kennedy Institute for Conflict Intervention. He holds a $\mathrm{PhD}$ in international security and terrorism from the Turkish Defence Sciences Institute. His thesis is on insurgencies and state sponsorships. His research interests include European security, CSDP and conflict resolution. 